\title{
UN ENFOQUE SOBRE LA MENTALIDAD EXTENDIDA DEL PERUANO CONTEMPORÁNEO
}

\author{
AN APPROACH ON THE EXTENDED MENTALITY \\ OF THE CONTEMPORARY PERUVIAN
}

Francisco Reluz Barturén

\begin{abstract}
RESUMEN
En el trasfondo de este artículo se encuentra una investigación que aúna la perspectiva filosófica con aspectos de la psicología de la personalidad, buscando reconocer e interpretar las diversas comprensiones que tenemos de nosotros mismos. En este sentido, tratamos de conocer nuestra identidad y axiología a fin de proyectarnos positivamente en el progreso y desarrollo, personal y social, en el contexto de la nueva sociedad.
\end{abstract}

\section{PALABRAS CLAVE:}

Mentalidad Extendida. Peruanidad. Identidad nacional, Conciencia nacional.

\begin{abstract}
In the background of this article is a research that combines the philosophical perspective with aspects of the psychology of personality, seeking to recognize and interpret various understandings that we have of ourselves. In this sense, we try to understand our identity and axiology in order to project us positively in progress and personal and social development, in the context of the new society.
\end{abstract}

\section{KEY WORDS:}

Extended mentality,Peruanidad (peruvianism), National identity, National consciousness.

* Docente ordinario de la Universidad Femenina del Sagrado Corazón: freluz@unife.edu.pe 
El interés en esta temática se debe a que es extendida la idea que parte de nuestra identidad cultural nacional es la indefinición, mediocridad y la 'viveza criolla', constituyéndose en un mito; mentalidad que paradójicamente, sostenemos, ha sido construida con el 'aporte' intencionado o no de muchos representativos intelectuales con cuyos escritos se han formado $\mathrm{y}$ se siguen formando las clases políticas y dirigenciales de nuestro país haciéndose extensiva en la ciudadanía. Por ello postulo la idea que, rescatando presupuestos interesantes de los mismos, desde la filosofía, apoyándonos en las investigaciones de la psicología social y la psicopedagogía, generemos una nueva comprensión de nuestro país más optimista y proactiva, progresista, que crea consistentemente una mentalidad extendida positiva.

Se ha dicho muchas veces que nuestro país carece de conciencia histórica, que no aprendemos de nuestros problemas, más aún que tenemos ciertas características culturales negativas que nos identifican y que, por ende, estamos como estamos, sin salir del subdesarrollo y con la gama de problemas que esto arrastra; pero ¿cómo se han ido forjando estas características con las cuales se nos identifica como país?, ¿son realmente ciertas?, ¿nos benefician? Estas y otras preguntas intento responder, consciente de que todo recurso humano si es adecuadamente conocido en sus capacidades y limitaciones, se constituye en potencial riqueza de desarrollo de un país, por tal razón se trata de investigar cómo ha sido y siguen siendo interpretados los problemas nacionales por parte de nuestros intelectuales y de qué manera su comprensión-visión de país han influenciado en la clase política y ciudadana desde nuestra formación como República. El cómo percibimos nuestro entorno social contextual genera una manera de actuar, de ahí la importancia de saber la manera en que ha sido interpretada la realidad nacional por nuestros pensadores más representativos (desde Manuel González Prada hasta Flores Galindo, pasando por Riva Agüero, Mariátegui, Víctor Andrés Belaúnde, Víctor Raúl Haya de la Torre, entre otros), haciendo un análisis crítico, a fin que no sólo conozcamos sus pensamientos, sino que, aprovechando tal recurso informativo, se genere una propuesta con la cual se pueda establecer, un adecuado y positivo conocimiento de nosotros mismos como peruanos.

Considero que parte de la problemática que vivimos como país se debe a la comprensión desesperanzada de los sucesos históricos vividos, generalizándose conductas dirigenciales y poblacionales inapropiadas. Lo que se debe buscar es que se enfatice, sin restar objetividad, una visión de país con una filosofía valorativa positiva, que generen adecuadas formas de convivencia, y esta no se logra sin el aporte de la psicología social y la psicopedagogía; de ahí que afirme que varios intelectuales peruanos a partir del análisis de sus textos, han 'contribuido' a extender un limitado y hasta falso reconocimiento de nuestra propia manera de ser peruanos con una tenue y 'desesperanzada esperanza', rescatando aquellos planteamientos que permitan generar una conciencia colectiva que se encamine al desarrollo integral de nosotros mismos y por ende de nuestra sociedad.

Sostengo dos tesis. En primer lugar: La confrontación y falta de integración nacional con propuestas de influencia foránea poco esperanzadas, son las características predominantes en los planteamientos que sostienen los intelectuales más representativos del 
país desde fines del s. XIX y durante el s. XX sobre la comprensión-visión del Perú, suscitando un problema de identidad nacional, en vez de formarlo (González Prada, Mariátegui, Víctor Andrés Belaúnde, Luis Alberto Sánchez, Víctor Raúl Haya de la Torre, Flores Galindo, Matos Mar).

La segunda tesis es que, el mantenimiento del problema identitario y falta de integración nacional, unida a psicopatologías con respuestas nacionales esperanzadas son las características predominantes en los planteamientos de los intelectuales representativos sobre la comprensiónvisión del Perú en esta primera década del s. XXI, iniciando reflexiones con visiones proyectivas de país que es necesario explicitar integradamente $\mathrm{y}$ difundir. (Flores Quelopana, Belaúnde Moreyra, Julio Rivera Dávalos), aunque también hay quienes se mantienen en la tesis anterior como José Luis Pásara y Fidel Tubino.

Estas dos tesis nos llevan a sostener en términos generales, que desde los inicios de la República nuestros intelectuales más representativos tienen por comprensión-visión del Perú, una mentalidad contrariada, pocas veces propositiva, extendiendo en el país una mentalidad poblacional con características negativas bastante arraigadas (falta de 'identidad' y 'conciencia' nacional, mediocridad, cortoplacismo, viveza criolla, etc.,) que debe cambiarse progresivamente a través de una plausible propuesta de talante filosófico sí, pero también con sustento desde la psicología social, la psicopedagogía y la educación.
Desde los enfoques psicologistas podemos recordar a tres intelectuales que tienen una lectura del Perú desde este ámbito: Luis Alberto Sánchez (19001994), Antonio Belaunde Moreyra (1927) y Gustavo Flores Quelopana (1959). En primera instancia podemos afirmar que Luis Alberto Sánchez en su texto 'Perú: retrato de un país adolescente' brinda una comprensión de país desde la psicología del desarrollo humano en plena expansión en su tiempo ${ }^{1}$, que como sabemos, es aquél ámbito psicológico que estudia cómo las personas crecen y cambian conductualmente a lo largo de sus vidas, propuesto también desde la psicología genética piagetiana. En efecto, Luis Alberto Sánchez usa metafóricamente las características y trastornos propios del adolescente aplicándolos al Perú como personalidad social, manifestando la búsqueda de identidad como país, el poco reconocimiento de su pasado, su vacío existencial y su confusa proyección de futuro, fundamentándolos con episodios históricos y características geográficas que confluyen en la construcción del ser peruano como una personalidad paradójica y problemática, pero que al mismo tiempo está esperanzadoramente por definirse. En esto constituye su tarea.

Por su parte, Antonio Belaúnde Moreyra, en amena conversación me manifestó que para la elaboración de su libro 'Perú: Persona, sombra y alma' se 'inspiró' en las investigaciones de Carl Gustav Jung (1875-1961), psiquiatra y psicoanalista suizo, para quien los problemas mentales se constituyen en modo patológico de procurar la autorrealización personal y espiritual; en tal sentido quien logra controlar estos

\footnotetext{
1 Recordemos a uno de sus máximos exponente Erik Erikson quien vivió entre el 1902 y 1994, desarrollando investigaciones sobre desarrollo infantil y crisis de identidad. Como intelectual, Luis Alberto Sánchez no estaría ajeno al conocimiento de estas investigaciones contemporáneas suyas.
} 
problemas reconstituye su personalidad. La labor del psicoanalista consiste, entonces, en ayudar al paciente a controlar sus patologías. En sus teorías Jung incluye aspectos históricos y mitológicos que lo llevan a concluir la relación entre los conceptos inconsciente individual-inconsciente colectivo.

El texto del embajador Belaúnde resume estos rasgos, nos recuerda mitos andinos, manifestando además que la superación de la psicopatología social que padecemos encontrará alivio en integración de nuestra espiritualidad religiosa andina y cristiana. Nos dice que (la crisis del Perú) es crisis de crecimiento propio de personalidades complejas y profundas que llegan a la madurez a través de un proceso tardio y difícil de 'desintegración positiva'. Por consiguiente, podemos intuir también que en la comprensión del Perú que tiene Don Antonio se encuentran rasgos de psicología transcultural y de la personalidad.

Gustavo Flores Quelopana, en su comprensión del Perú piensa que la personalidad social tiene la psicopatología neurótica manifestada a través de su temor a alcanzar el éxito (lo que llama éxitofobia) y su tender hacia la propia minusvaloración como mantenimiento del estatus quo de falso bienestar al dejar las cosas tal como están, sin superarse (llamado por Flores fracasofilia), puesto que, siguiendo nuestro himno somos un pueblo de 'humillada cerviz', serios complejos discriminatorios que debemos cambiar. Su propuesta es que carecemos de modelos positivos de emulación moral, de ahí que en la búsqueda de arquetipos admiremos áulicamente todo lo extranjero.

La neurosis, como característica psicopatológica, se manifiesta particularmente con una obsesa ansiedad $^{2}$ mostrada en comportamientos inadaptados que, Gustavo Flores asigna a nuestra personalidad colectiva. Flores en tal sentido, recibe una influencia desde el psicoanálisis, puesto que es desde aquí donde se considera que la neurosis consiste en la respuesta de un sujeto como solución de compromiso entre el deseo y la defensa, cuyas formas nacionales serían la éxitofobia y la fracasofilia.

Además encontramos que Flores Quelopana en su comprensión de país asume las tendencias psicoanalíticas de Alfred Adler y Otto Rank. Del primero el estudio del sentimiento de inferioridad, que si no es superado ocasiona el descontrol de mecanismos compensatorios determinando actitudes egocéntricas, sobrecompensaciones, incluso, la huida del mundo real y sus problemas; o que al intentar ser evitado conduce a manifestaciones de una voluntad poco razonable de poder y dominio, comportamiento antisocial, intimidación y la tendencia a la tiranía política. En su lectura sobre el Perú, Gustavo atribuye todas estas características a nuestro colectivo social ${ }^{3}$.De Otto Rank, Flores Quelopana toma la idea de que las perturbaciones neuróticas se inician con el trauma del nacimiento más aún si hay complicaciones en el parto, lo mismo

2 La ansiedad es tópico angular de la teoría y la práctica psicoanalítica, asumiéndola como un tipo de experiencia que implica una reacción contra ciertas situaciones que el sujeto considera peligrosas o riesgosas, tales como según Freud, son el miedo a ser abandonado, a perder el objeto amado, el miedo a la venganza y al castigo, y la posibilidad de castigo por parte del superyó.

3 Dice Flores Quelopana: 'La éxitofobia y la fracasofilia son partes substanciales de nuestra neurótica 'humillada cer$v i z$ ', como componentes inherentes y naturales a nuestro comportamiento social. Presidentes que pretenden perennizarse 
asume nuestro filósofo cuando afirma que nuestra neurosis hunde sus raíces que perduran en nuestro subconsciente en el choque emocional histórico entre lo indígena e hispánico.

Los rasgos psicologistas de parte de nuestros intelectuales han sido tomados para la comprensión de los problemas nacionales y para caracterizarnos incluso negativamente, no así sucede con las lecturas comprensivas del Perú con rasgos filosóficos y psicológicos humanistas que a nuestro entender son más libres y menos dependientes de los humanismos ya existentes, revistiéndose así de concepciones sui generis. Así, pues, tenemos a Don Jorge Lazo Arrasco (1928), con su humanismo del autoconocimiento y valoración, dotado de un existencialismo más como método que como asunción doctrinaria, puesto que el existencialismo de Lazo está lleno de sentido que se va adquiriendo cotidianamente y no al final de la existencia; y, por otro lado, se trata de un existencialismo espiritualizado, optimista, voluntarista ${ }^{4}$ que también cree está latente en el peruano pero que la educación, por medio de la filosofía y la psicología, debe encargarse de hacérselo explicitar.

\section{Mentalidad extendida del intelectual peruano contemporáneo}

Podemos catalogar a la intelectualidad peruana contemporánea en cinco grandes grupos de abigarrada gama: Los academicistas altamente especializados en planteamientos foráneos, los nostálgicos nacionalistas, los críticos apesadumbrados, los 'prácticos' teoréticos y los revolucionarios.

Los primeros se caracterizan por su excelencia en el saber, principalmente filosófico; especialistas en Kant, Husserl, Heidegger, Dewey, Rawls o Vattimo, generalmente con un grado académico europeo conseguido con mucho esfuerzo y tesón. Muchas veces su sapiencia especializada se ve opacada por la pretenciosa actitud que liga con lo soberbio de 'asignarse' de ser quienes mejor interpretan a tal o cual filósofo, e incluso 'acercarse' mejor -es decir'genuinamente', a sus planteamientos y, en consecuencia, rechazan lo que según sus paradigmas es una mala interpretación o un error, o peor aún atrevida ignorancia, cualquier tesis o lectura interpretativa sobre 'los grandes de la filosofía universal' que discrepe con las suyas. Su alta especialización crea admiradores avasallados a través de las cátedras; sus bien elaboradas clases de alta calidad académica serían mejor aprovechadas por los oyentes y estudiantes si se preocuparan no tanto para demostrar lo mucho que saben -de lo cual nadie duda - sino, para que principalmente sus oyentes aprendamos. Muchos de los academicistas se olvidan de explicitar una comprensión-visión del Perú, diciendo muy poco o casi nada sobre el tema.

- Fujimori fue el último-, dirigentes exitosos defenestrados por celos... y el mantenimiento del bajo perfil en la empresa, en el hogar, el barrio, el cuartel, el colegio, la fábrica, la universidad y el ministerio resulta siendo el santo y seña más seguro para librarse de las ojerizas ajenas - previa fraterna comunión en el delito, lo etílico, la obscenidad, la indignidad o lo erótomano' (Los Peruanos ¿por qué somos emprendedores sin ser innovadores?, p. 22-23)

4 Nos dice, por ejemplo, en su Conversando con Don Jorge: 'La vida no debe medirse por los yerros y equivocaciones, sino por los aciertos. Sabiendo que ella, me refiero a la vida, es un gran campo de batalla, con héroes y derrotados. En cual de los grupos estamos, es la cuestión... Es una escuela de desarrollo, donde hay que aprender a la fuerza' o 'El hombre que envidia no es hombre. El hombre que vale no envidia ni critica. El hombre que vale, respeta. En palabras de San Francisco de Asís es agradable decir: 'Que bueno que tú existas'. Cfr. JLA.§§ 155-156 en el apéndice de esta investigación. 
Por otro lado se encuentran los nostálgicos nacionalistas, cuyos discursos se arraigan en una comprensión asincrónica de la historia. Así pues tenemos los que tienen un valioso conocimiento de la vida precolombina e incásica pero pretenden aplicar este sistema a nuestro actual contexto. Otros, se maravillan del coloniaje y sus 'grandiosos aportes' a nuestras civilizaciones esparcidas por los cuatro suyos. Algunos de los muchos nostálgicos nacionalistas exacerban los discursos de Mariátegui o de Haya o de Velasco e incluso de Fujimori sin ver sus limitaciones o sus muchos defectos. Su amor al Perú se ve ofuscado por la 'rabia' de los conflictos pasados que desde su entender siguen irresueltos trayéndonos las desgracias sociales, políticas y económicas contemporáneas, como dice certeramente el historiador Guillermo Rochabrún: "a menudo el pasado ha sido invocado simplemente para condenarnos" 5 .

Para los críticos apesadumbrados, particularmente desde la vertiente de los estudios sociales, la realidad del Perú consiste en la crisis como condena perenne, insalvable. Entre desbordes, leviatanes apedreados, frustraciones anhélicas, achorados, acholados y subculturas combis, al país no le queda otra salida que sobrevivir en medio de 'este' caos. Sus sesudos análisis enfatizan la realidad presente y sus causas que, generalmente son lo mismo que los efectos, suscitando un círculo vicioso, careciendo de visiones proyectivas o al menos, sugerentes de nuevos caminos.
En el caso de los 'prácticos' teoréticos son aquellos que, especializados en las contemporáneas filosofías éticas, políticas y económicas, realizan comentarios de la realidad nacional con fuertes sesgos sectorizados y de élite desde el gabinete, sus conclusiones la realizan conociendo al Perú a través de filtros intelectuales igual de sesgados. Al igual que los academicistas altamente especializados, en el debate y fuera de él, se jactan de sus 'buenos argumentos' felicitando con los mismos calificativos a quienes piensan como ellos y criticando destructivamente, en todo contexto, a los que se contraponen a sus planteamientos. Califican a sus oponentes intelectuales como 'pocos serios', 'falaces', 'conservadores' y hasta retrógrados.

En nuestro país, este grupo de intelectuales ha centrado sus preocupaciones en los temas de derechos humanos, tanto en su fundamentación, como en su práctica y defensa. Una loable y valiente labor, sin duda alguna, en nuestro país donde la violación de los derechos es una constante; sin embargo, un amplio sector de la población percibe que la defensa de los derechos no es aplicado con igual justicia, más aún, los diversos planteamientos de los 'prácticos' teoréticos han sido utilizados por grupos terroristas y sectores violentistas para justificar sus actos asesinos y vandálicos, incluso defenderlos escudándose bajo el concepto de violación de derechos, creando la paradoja de debilitamiento de las instituciones del Estado 6 .

5 G. Rochabrún. Ser historiador en el Perú. En: Revista Márgenes n0 07. SUR, Casa de Estudios del Socialismo. Lima. Enero 1991. pp.130-145.

6 Tal es el caso de terroristas que defienden y expanden sus ideologías que ya están en libertad o se han acogido al asilo político en países europeos, cuyos remanentes actuales están vinculados al narcotráfico y siguen asesinando a campesinos, ronderos o fuerzas del orden. Por otro lado, no es el único elemento debilitante de la institucionalidad, también están, principalmente, la corrupción política, la ineficiencia e ineficacia de las propias instituciones estamentales. 
Finalmente, los revolucionarios que buscan una transformación total y radical del contexto actual, a estos los catalogamos en dos vertientes: los revolucionarios de las ideas, cuyos planteamientos a contracorriente más de las veces caen en el vacío, sus esfuerzos intelectuales que reflejan valentía y autenticidad de intención son de largo plazo, lo que demora el cambio de mentalidad generacional. Los otros son los revolucionarios de las armas, quienes carecen del poder de las ideas como persuasión y transformación del Perú, las ideas que creen tener son dogmas y lemas inconexos sujetos al líder mesiánico todopoderoso entre sus huestes; a falta de ideas, proyectos, propuestas y métodos, atemorizan por el abuso de las armas engendrando más violencia, desintegración, pobreza y subdesarrollo.

Nos preguntamos ¿cómo fusionar la acuciosidad investigativa rigurosa de los academicistas altamente especializados en planteamientos foráneos, para observar y pensar los problemas nacionales, con el amor y la alta valoración por lo nuestro característico de los nostálgicos nacionalistas, junto a la agudeza de los críticos apesadumbrados, la preocupación por la sociedad y sus derechos propio de los 'prácticos' teoréticos y la radicalidad esforzada de los revolucionarios, sin atacar personas e ideas pero sí los problemas comunes? ¿cómo unirnos bajo un solo objetivo: el auténtico desarrollo integral del Perú?

\section{Mentalidad extendida en el peruano de a pie}

Considero que existe una doble mentalidad extendida en el peruano contemporáneo de a pie: los indiferentes ante cualquier problemática nacional, constituida en su mayoría por jóvenes que aún no están concientizados de la importancia que tiene su quehacer como grupo poblacional para el desarrollo del país. Aquí un interesante ámbito de nuestro trabajo como profesionales jóvenes, filósofos y psicólogos. No les interesan asuntos públicos, desconociendo la realidad nacional y disfrutando el día a día, sazonado básicamente con la diversión dispersante que cada vez llega a edades más tempranas; por ejemplo, se suele ver penosamente, por los medios de comunicación como en vez de ir a sus instituciones educativas, se les encuentra en discotecas ambulantes trastornándose con alcohol y drogas, los llevan a las comisarías y llaman a sus padres que los recojan por ser menores de edad.

La indiferencia alcanza también a los grupos poblacionales adultos ocupados más en sus intereses particulares, dedicándose en buena hora a su trabajo; pero otros en actos delincuenciales, cada vez en cantidades más alarmantes.

La indiferencia por los asuntos públicos es un asunto muy grave que trae consecuencias negativas para la direccionalidad de un país, puesto que una sociedad mayoritariamente poco informada y formada en temas de interés nacional es fácilmente manipulable por ideologías nefastas de diversa índole, y peor aún, se carecerá del criterio suficiente para evaluar propuestas políticas de los candidatos a los diferentes cargos de los poderes centrales del Estado cla consecuencia? Congresistas y políticos que son más conocidos por sus escándalos y actos de corrupción que por sus propuestas.

Si hay indiferentes, hay otro grupo interesado que busca mantenerse en el poder político. Existe un antiguo adagio 
que expresa: 'una de las razones para que el mal se extienda, es que los buenos no hagan nada por impedirla'. Se dice también que es propio del peruano de hablar y decir sin ser directo, o expresarse de manera contundente ante un reclamo, cualquiera que sea el ámbito... es la influencia de la 'humillada cerviz', felizmente ahora desterrada del Himno Nacional, hermanada paradójicamente con el 'somos libres'.

De los interesados en los asuntos públicos, existen dos grupos. Los interesados porque creen en el poder político como medio de agenciarse económicamente y de privilegios; y los interesados que conociendo la realidad nacional expresan taxativamente que todo está perdido y no hay solución posible ${ }^{7}$. Éstos últimos, consideramos, provienen de la influencia que nuestros intelectuales de mayor prestigio han formado. Tanto los indiferentes como los interesados, tienen algo en común: la total desconfianza en los poderes del Estado, que los lleva a decir en el colmo de la indiferencia y el conocimiento 'no importa que roben pero que hagan algo' respecto a sus autoridades; y es que, quienes integran las instituciones hacen 'méritos' para que así sean tenidos, cercándose el círculo vicioso de país sin rumbo, con proyectos a corto plazo.

Sin embargo, está surgiendo desde hace unas décadas, un creciente sentimiento de autovaloración del propio ser peruano en las grandes mayorías, de la identidad que siempre tuvimos y que ahora estamos paulatinamente tomando conciencia, identidad esforzada, progresista, orgullosa que debemos alentar desde ahora y para siempre.

\section{Comprensión-Visión propositiva del Perú contemporáneo}

Los países tienen cada uno su propia problemática pero la historia de los mismos oscila de manera parecida en: choques culturales y raciales, situaciones violentas (conflictos civiles y guerras internas $y / o$ por fronteras $u$ otros intereses), pobreza, corrupción, y en algún momento características de subdesarrollo. Y esto es lo mismo en EE.UU, Japón, China, Alemania, Francia y España. Basta revisar sus historias para dar cuenta de ello. Pero la gran pregunta es ipor qué ellos alcanzaron el desarrollo, y los países sudamericanos no, particularmente el Perú? Pregunta difícil de responder por los diversos factores implicados en ella; sin embargo, esbozamos una de las posibles razones: sus historiadores e intelectuales ven el vaso medio lleno y no medio vacío, su objetividad crítica está acompañada en el énfasis de cohesión y encuentro de sentido de su realidad contextual con visión propositiva plausible y no en la dispersión contrapuesta con que se llevó y aún se lleva a cabo la comprensión de los problemas sociales de nuestra realidad nacional ${ }^{8}$.

Las dos tesis serían desesperanzadoras si no la acompaña una propuesta, y es la

7 Como por ejemplo el difundido video 'Vivos y Plebeyos' dirigido por Matías Vega y Luis Soldevilla.

8 Algunos ejemplos: la historiografía China desde la antigüedad unida a la filosofía buscaba la formación moral de los ciudadanos, el erudito Marcelino Meléndez y Pelayo (1856-1912) quien en su Historia de los heterodoxos españoles encuentra el hilo conductor que subyace en el pensamiento español por más contrarios que parezcan entre sí: la religiosidad; o tal vez como figura emblemática Hegel, quien considera que la historia de la humanidad hasta su época se sintetiza en lo que ahora es Alemania; los franceses AdolpheThiers (1797 1877) autor de Historia de la Revolución Francesa o Pierre Joseph Proudhon (1809-1865) quien rechazaba el uso de la fuerza de los sistemas políticos, o que la sociedad no puede ser transformada por un plan preconcebido. 
que vengo a proponerles, y desde la filosofía de una mentalidad extendida positiva tenga por valiosos aliados los aportes de la psicología social y la psicopedagogía a fin de ir aplicándola y hacerla extensiva. La propuesta es: El Perú es una síntesis del progresivo desarrollo por voluntad y criterio nacional frente a los acontecimientos históricos que le ha tocado vivir. Pienso que esta comprensión-visión del Perú contemporáneo ayuda propositivamente a nuestro progreso y desarrollo integral como país.

Para una comprensión-visión propositiva de nuestro país, esbozamos respuestas, a las preguntas filosóficas fundamentales del es y del debe, aplicadas al Perú: ¿Qué es ser peruano?, y ¿Qué es el Perú?, teniendo por hilo conductor el hace en sus tres formas: como presente del pasado (lo que hizo), presente del presente (lo que hace) y como presente del futuro (lo que debería hacer).

Respecto a la pregunta ¿Qué es ser peruano? auxiliamos por la antropología filosófica, la ética y la axiología aplicadas a la observación fenoménica de nuestra praxis gracias a los aportes desde la psicología, creemos que es un humano que sintetiza positivamente todo lo mejor de su historia, que se erige perseverante superando sus problemas, que se enorgullece de su rico pasado y de los logros que con esfuerzo alcanza cotidianamente, cuya identidad antropo-axiológica es el esfuerzo por construir siempre un mejor porvenir, identidad latente que los intelectuales debemos contribuir a su toma de conciencia y explicitación constante.

\section{A la pregunta ¿Qué es el Perú?} En primer lugar, es un territorio, uno de los más extensos, bellos y ricos en recursos de esta parte del Nuevo Mundo, admirada por aborígenes y deseada por los conquistadores, aún hoy. Es esta riqueza que debemos aprovechar no para explotarla abusivamente en beneficio de pocos como Estado-vendedor, sino como Estado que se dirige cual hábil gerente sabio administrador de sus recursos naturales y humanos, capaz de ser eficiente y eficaz en sus acciones. Pero también, el Perú deja de ser un concepto moderno que aún estaba por definir, según la mayoría de intelectuales a lo largo de nuestra historia republicana, sino que ahora, conociéndonos más, afirmamos que somos país y nación con identidad mestiza en su raza y sus valores cual síntesis excelente. Sin embargo, para que este reconocimiento de nuestra identidad se haga extendida se debe unir al país homogenizando los beneficios de servicios públicos de calidad, y al mismo tiempo haciendo extensivo lo que somos ayudados por la psicología social y la psicopedagogía.

Poseemos grandes valores con los cuales, podemos ir progresando aún más: El emprendedorismo voluntarista; nuestra variada, rica y aún no explotada ni bien administrada geografía; y, mejor aún, la paulatina toma de conciencia de nuestra identidad nacional, junto a nuestra solidaridad mancomunada.

Por lo expuesto, concluimos que el Perú -repitiendomi propuesta-esuna síntesis del progresivo desarrollo por voluntad y criterio nacional frente a los acontecimientos históricos; esta es, una comprensiónvisión del Perú contemporáneo que ayuda propositivamente a nuestro progreso y desarrollo integral como país, ahora creo que este modesto aporte, sea asumido como un reto por los profesionales de la mente y el espíritu, de tal manera que vaya creándose una sociedad mentalmente saludable, optimista, segura de sí, dispuesta a su desarrollo integral. 


\section{REFERENCIAS:}

AA.V. (2008). Perú en el s. XXI. Luis Pásara, editor. Lima: Fondo Editorial de la Pontificia Universidad Católica del Perú

BELAUNDE MOREYRA, A. (2008). Perú: Persona, sombra y alma. Lima:IIPCIAL.

COTLER, J. (1994). Política y sociedad en el Perú. Cambios y continuidades. Lima: Instituto de Estudios Peruanos.

DEVÉS Valdés, E. Cartas a la intelectualidad, estudiantes universitarios y a todos los profesionales del conocimiento de América Latina. En: Revista Acta Herediana, Universidad Peruana Cayetano Heredia. Vol.41, Abril Septiembre 2007; pp. 40-49. Lima.

ÉLGEGREN Reátegui, F. (2006). Construyendo ciudadanía desde el Estado y la sociedad en el Perú. En: Revista COMUNIFE, pp. 42 - 57. N0 6. Enero - Diciembre.

FELDMAN, R.S. (1997). Psicología. Con aplicaciones para Iberoamérica. México: Mc. Graw-Hill - Interamericana.

FLORES QUELOPANA, G. (2008). Los peruanos ¿por qué somos emprendedores sin ser innovadores? Lima: Fondo Editorial IIPCIAL.

IWASAKI CAUTI, F.(1988). Nación peruana: Entelequia o utopía. Trayectoria de una falacia.Lima: Centro Regional de Estudios Socio Económicos.
LAZO ARRASCO, J. (1997). La educación: único camino que le queda al hombre. Lima: Editorial Garcilaso.

MATOS MAR, J. (2004). Desborde popular y crisis del Estado. Veinte años después. Lima: Fondo Editorial del Congreso del Perú.

ROCHABRUN, G. (1991). Ser historiador en el Perú. En: Revista Márgenes n0 07. SUR, Casa de Estudios del Socialismo. Lima. pp. 130 145.

SANCHEZ, L.A. (1963). El Perú: Retrato de un país adolescente. Lima: Departamento de publicaciones de la UNMSM.

SCHULDT, J. (2005). ¿Somos pobres porque somos ricos? Recursos naturales, tecnología y globalización. Lima: Fondo Editorial del Congreso del Perú.

TUBINO, F. (2007). Perú: la ausencia de sintesis. Ensayo, publicado digitalmente por la PUCP.

TUBINO, F. (2007). Ensayo sobre la cultura en el Perú. Ensayo, publicado digitalmente por la PUCP.

ZEVALLOS VERA, M. (1988). Integración filosófica, cambio social y conciencia nacional. Arequipa: Publicaciones de la Universidad Nacional San Agustín.

ZEVALLOS VERA, M. (1959). Crítica histórica y educación social. Arequipa: Editorial Universitaria. 